\title{
Resenhas
}

\section{EM BUSCA DE SAUSSURE}

\section{$\dot{A}$ la recherche de Ferdinand de} Saussure, de Michel Arrivé. Paris: PUF (Formes Sémiotiques), 2007, 229 p.

\section{Waldir Beividas}

Doutor em Lingüística e Semiótica pela USP (1992); pós-doutorado pela EHESSParis (1999); Professor do Programa de Pós-Graduação em Teoria Psicanalítica (1993-2006); Professor do Programa de Pós-Graduação em Lingüística e Semiótica na USP (desde 2007).

Ano passado surgiu no cenário editorial este importante livro de Michel Arrivé. Bela homenagem vem à luz, justo no ano do sesquicentenário de nascimento do principal mentor dos estudos da lingüística moderna - Ferdinand de Saussure [1857-1913] — justo no centenário do primeiro Curso de Lingüística Geral [1907] Por certo, diversos eventos, congressos, simpósios se deram ao longo do ano, mas o porte de um livro inteiro dedicado ao mestre genebrino sobressai como evento ímpar.

Meticuloso conhecedor de Saussure, participante ativo na discussão crítica do cenário lingüístico desde meados do século findo, Arrivé é, decerto, muito mais conhecido, lido e estudado no âmbito da lingüística e da semiótica. Mas o campo psicanalítico, freudiano e lacaniano, recebeu atenção primorosa, a mais fina e empenhada, dentre todos os lingüistas, de qualquer tempo.
Dois livros anteriores, inteiramente dedicados à interface entre lingüística e psicanálise, já tiveram tradução brasileira: Lingüística e psicanálise. Freud, Saussure, Hjelmslev, Lacan e os outros (São Paulo: Edusp, 2001) e Linguagem e psicanálise. Freud, Saussure, Pichon, Lacan (Rio de Janeiro: Zahar, 1999). A resenha deste último, em Ágora [v.II n. 2, 1999, p.134], o considerou "seguramente um dos livros mais importantes publicados nos últimos anos".

Nesses livros, Arrivé equilibrou a presença de Saussure e Lacan, o pensador lingüista e seu leitor psicanalista, num cenário finamente pesquisado e argumentado. Em meio a suas próprias e apropriadas "releituras" de Saussure, trouxe-nos a experiência singular, difícil e altamente esclarecedora: extrair da sua leitura de Lacan, a mais plausível leitura de Lacan extraída de Saussure.

Em busca de Ferdinand de Saussure apresenta cenário diferente. Conquanto aqui e acolá o autor põe Lacan em cena, é Saussure o centro das atenções. Desejo vintenário de dedicar o livro inteiro ao lingüista de Genebra, confessa que todo novo livro de outrem, dedicado a Saussure, nesse período, lhe batia à cara como um "insulto". Era, pois, hora de "responder ao insulto com insulto” (p.3), isto é, com o seu livro sobre Saussure.

O novo livro beneficia o leitor a partir de um novo dado. Um evento histórico, altamente significativo, ocorreu nos últimos anos: em 1996, foram localizados 
novos manuscritos de Saussure, publicados em 2002 sob o título de Escritos de lingüística geral, e já traduzidos para o português (Cultrix: 2004). A descoberta está agitando o mundo da pesquisa saussuriana e Arrivé se destaca como um dos mais assíduos freqüentadores do pensamento do mestre de Genebra, agora recuperado no frescor dos novos manuscritos.

Sempre com a meticulosidade de um arqueólogo textual, o autor se apresenta como leitor do pensamento de Saussure há mais de meio século (p.1). Nas reflexões dessa busca do criador da lingüística moderna e sem mistificar o pai da lingüística moderna, revela que a obra saussuriana é na verdade a origem de uma "mutação considerável na evolução da disciplina”, mesmo sob o aspecto lembrado como "insólito”: o de que Saussure "não publicou o que escreveu e não escreveu o que se publicou sob seu nome" (p.9-10).

"Uma vida na linguagem", primeiro capítulo, percorre um inventário cronológico das atividades de Saussure, sobre as questões da linguagem, centrado na sua vida intelectual. O propósito epistemologicamente rigoroso é "situar a reflexão de Saussure nas condições históricas de sua elaboração" (p.11). Notícias cronológicas sobre a família, a vida, a carreira e as atividades, destaque-se nesse entremeio um texto que, em 1894, o jovem lingüista prepara (sem concluir) em memória ao importante lingüista da época, W. D. Whitney, reflexão que Arrivé considera "uma das meditações mais profundas e audaciosas de Saussure sobre os problemas da linguagem e da semiologia” (p.26).

Segue-se um "modesto ensaio de releitura" sobre o Curso de lingüística geral. O leitor certamente discordará do modesto título do segundo capítulo, quando se depara com nada menos do que 50 páginas nas quais observa uma situação diferente das outras precisões e leituras minuciosas levadas a efeito nos dois livros anteriores. Aqui Arrivé tem nova baliza: os novos documentos descobertos, escritos do punho próprio de Saussure. Interroga o Curso a partir das reflexões totalmente inéditas, intituladas "Sobre a essência dupla da linguagem”, nada menos do que as 70 páginas que abrem os Escritos.

É digno de se ressaltar algo de fundamental, sobretudo diante do modo como o pensamento de Saussure circula e pouco a pouco fica desdenhado no campo psicanalítico. Trata-se justamente de evitar o erro que consiste em deduzir que Saussure exclui do campo da lingüística tudo o que seria utilização pelo "sujeito falante”. Relê, na perspectiva ajustada aos novos manuscritos, o signo saussuriano, a arbitrariedade do signo lingüístico, e discussões suscitadas em Pichon, em Benveniste, em Toussaint, em Milner, e suas próprias avaliações de releitor. O capítulo contempla o que de mais atual, crítico e arguto se pode hoje ler sobre essas questões. Outras preciosidades: a questão da linearidade do signo, mormente restritas ao significante, mas que aqui se estendem ao significado, discussões sobre a noção de valor, das relações sintagmáticas e paradigmáticas, sincronia e diacronia.

O capítulo terceiro traz informes sobre a lenda na carreira do lingüista, no interior da Semiologia. E nota que a pesquisa legendária é praticamente "co-extensiva” no tempo com a pesquisa lingüística (p.88), sendo um ponto curiosamente observado: o "silêncio" no Curso sobre a semiologia legendária.

"Fala, discurso e faculdade da linguagem na reflexão de Saussure" é o título do quarto capítulo. A temática é de toda a importância diante das relações da lingüística com a psicanálise. Atento ao estatuto da fala, entre o que foi retido no Curso e o que se lê nos Escritos, o propósito 
é demolir dois "rumores" funestos: a) de que Saussure (do Curso) teria eliminado de seu projeto teórico toda a atividade do sujeito falante. Arrivé dá voz ao autor dos Escritos, que critica a escola de F. Bopp justamente por ter dado à língua "um corpo e uma existência imaginários fora dos indivíduos falantes" (p.102). Saussure julgava mesmo uma conquista de seu tempo ter situado língua e linguagem no seu "verdadeiro lugar exclusivamente no sujeito falante seja como ser humano seja como ser social" (ibid); b) o rumor inverso, de que a parte mais importante de Saussure seria efetivamente voltada para a parole. Condena os dois rumores como extremados, sem respaldo seguro em Saussure.

Com serenidade, retoma os efetivos pronunciamentos de Saussure sobre a fala, o discurso e a faculdade de linguagem. Procura "precisar a situação" para evidenciar que a lingüística da fala, do discurso ou mesmo da enunciação (p.110) não fora de modo algum descartada por Saussure, impressão talvez deixada pelo Curso. Mesmo se não "realizada por ele" permaneceu como "programa no mais alto ponto sedutor e promissor, mas não levado a efeito" (p.116).

Arrivé mostra que a oposição langue/ parole que no Curso atribui algo de pejorativo ao campo da fala, é muito menos marcada ou polarizada no Saussure "autêntico" no qual a fronteira é um tanto mais "porosa" (p.114). Dentre as "soluções" saussurianas destaque-se a que faz "integrar na língua os fenômenos sintagmáticos previamente situados na fala” (p.115). A discussão interessa sobremaneira ao campo psicanalítico, quando com facilidade e pressa se aposta num distanciamento do Lacan da lalangue, o assim chamado último Lacan, por relação ao Lacan da linguagem, o primeiro, forçando-se uma operação ilegítima de opor língua, fala, linguagem, como se fossem distintos e irreconciliáveis campos da atividade linguageira normal (e inconsciente).

Em seguida, investiga a questão do Tempo em Saussure, sendo a maiúscula a própria letra manuscrita do lingüista. Num pensamento de caráter "profundamente dialético" (p.119), demonstra que o tempo é central em Saussure e que os editores do Curso teriam feito perder a "gravidade" que Saussure lhe conferia (p.122). Introduz esclarecedores argumentos sobre o tempo diacrônico e o tempo da linearidade, a repercussão da linearidade não apenas no significante, mas estendida ao significado, apoiado em proposições fortemente audaciosas e elucidativas do lingüista dinamarquês, continuador de Saussure, L. Hjelmslev.

"Saussure às voltas com a literatura" é o tema seguinte, em que Arrivé confessa suas "perplexidades": a) o Curso deixa em posição marginal a noção de literatura, enquanto que a pesquisa de tipo literário — anagramas e lendas - obteve interesse perene e constante ao longo de todo o itinerário de Saussure; b) a relação entre literatura e escrita em Saussure, o privilégio concedido ao significante "incorpóreo", dado como exclusivamente sonoro (“imagem acústica”), ou seja, convocando a pesquisa a se voltar à questão: os textos anagramáticos, objetos de inúmeras análises saussurianas, terão eles um regime propriamente literário?

Por fim, os dois últimos capítulos tematizam respectivamente: a influência de Saussure no nascimento da semiologia de R. Barthes e da semiótica de A. J. Greimas, e uma reflexão de Saussure sobre a naturalidade da relação entre a linguagem e a voz humana.

Perseguindo enfim, as "porosidades" — termo seu de escolha antiga — entre o campo da linguagem e do inconsciente, da 
lingüística e da psicanálise, eis que nesse empenho infatigável Arrivé está prestes a publicar em outubro próximo, pela PUF, mais um rebento dessa perseguição: 0 lingüista e o inconsciente. Que seja bem-vindo!

Recebida em 3/6/2008.

Aprovada em 25/6/2008.

Waldir Beividas

waldirbeividas@gmail.com 